\title{
Teslim Tarihi Problemi ve İnovatif Bir Karar Modeli Önerisi
}

\section{$\ddot{O} z$}

Siparişe üretim yapan firmalarda ürünlerin teslim tarihinin belirlenmesi, firmanın karlıllğg ve müssteri memnuniyeti açısından oldukça hayati öneme sahiptir. Çünkü, müşteriler bir siparişi onaylarken hem ürünün fiyatından hem de teslim tarihinden memnun olmalıdır. Erken verilecek teslim tarihleri üretim programında yı̆̆llmalara neden olabilir ve geç teslim tarihleri sipariş ve müşteri kaybına sebep olmaktadır. Bu çalışmada, siparişe üretim ortamı için teslim tarihi problemine getirilen çözüm önerileri araş̧tırılmıştır. Yapılan önceki araştırmalar kapsamlı bir şsekilde incelenerek teslim tarihi problemine çözüm önerisi olacak inovatif bir doğrusal karar modeli önerilmiştir.

Anahtar Kelimeler: Siparişe Üretim, Teslim Tarihi, Sipariş Stralama.

Jel Kodları: M11, M31.

\section{Delivery Date Problem and An Innovative Decision Model Proposal}

\begin{abstract}
Determining the delivery date of the products in the make-to-order firms has a vital importance in terms of profitability of the firm and customer satisfaction. Because customers must be satisfied with both the product price and the delivery date when approving an order. Early delivery deadlines can cause accumulation of the production schedule, and the late delivery dates lead to lose orders and customers. In this study, the solution offers for the delivery date problem of the make-to-order production environment is examined. By taking a long hard look at the previous researches, an innovative linear decision model has been used to propose a solution to the delivery date problem.
\end{abstract}

Keywords: Make to Order, Delivery Date, Order Ranking.

Jel Codes: M11, M31.

\footnotetext{
* Doktora Öğrencisi, İstanbul Üniversitesi, Fen Bilimleri Enstitüsü, Enformatik Bölümü, cakturk@kilis.edu.tr ORCID: http://orcid.org/0000-0003-3764-3862

** Prof. Dr., İstanbul Üniversitesi, Enformatik Bölümü, sevincg@yahoo.com

ORCID: http://orcid.org/0000-0001-8537-7111
} 


\section{Giriş}

Siparişe üretim yapan her firmanın, müşterilerine teslim tarihi ve fiyat teklif ederken, teslim tarihi ve fiyat belirlemede uyguladığı bir takım politikalar olmak zorundadır. Rastgele olarak gelen taleplere sırayla tarih veren bir firma, kaynaklarını verimli bir şekilde kullanamaz veya yığılan sipariş sırası için gelen yeni taleplere çok geç teslim tarihi teklif ederek müşterilerin kaybına ve dolayısıyla pazardaki payında azalmaya sebebiyet verir. Bu sebeple teslim tarihine etki eden tüm faktörlerin firma politikası ve öncelikleri doğrultusunda bir dengede tutulması hem işletmenin karlılığı hem de müşteri memnuniyeti ve müşteri sadakatinin korunması açısından oldukça önemlidir. Müşterilerin sipariş talepleri için fiyat ve teslim tarihi belirlerken birçok kriter bu tarih ve fiyat belirleme olayında etkilidir. Örnek kriterler şu şekildedir: Müşteri ile yıllık bazda çalışılan sipariş miktarı, siparişin parasal tutarı, sipariş sıklığı, müşteri ile çalışılan yıl sayısı, müşterinin pazardaki payı, müşterinin talep ettiği teslim tarihi, müşterinin kabul ettiği ürün fiyatı, müşterinin sipariş tutarını ödeme zamanı ve ödeme şekli vb.

Siparişlere teslim tarihi ve ürün fiyatları belirlemek amacıyla firma politikaları çerçevesinde problemi çok kriterli karar yapısı olarak göz önünde bulundurarak hem müşteri memnuniyetini sağlayacak, hem işletme gelirlerini belirli bir dengede tutacak, işletmelerin kendi amaçları ve kriter ağırlıklarına göre teslim tarihi ve ürün fiyatı belirleyebilecekleri, sipariş gelirlerini bu amaçla yönetebilecekleri, satış pazarlama birimleri ile üretim birimleri arasındaki koordinasyonu sağlayacak karar destek sistemleri bu açıdan oldukça önem kazanmaktadır.

\section{Literatürdeki Çalışmalar}

Literatürde teslim tarihi problemi için genelde iki farklı terim kullanılmaktadır. Bunlardan birincisi ve en çok kullanılanı teslim tarihidir. Teslim tarihi ürünün müşteriye teslim edileceği tarihi belirler. Diğer kavram ise teslim süresidir. Teslim süresi, bir siparişin işlenmeye başlanmasından teslim edilmesine kadar geçen süredir. Yani teslim tarihinden işleme başlama tarihi arasındaki farkın gün olarak ifadesi denilebilir. Teslim tarihi için öne sürülen algoritma veya kurallar ya siralama tabanlı ya da teslim tarihi atama tabanlıdır. Siralama tabanlı olanlarda önce siparişler sıralanır daha sonra sıralanan her bir siparişe işlemlerin bitme süresine göre bir teslim tarihi belirlenir. Teslim tarihi atamada ise öncelikle siparişlere teslim tarihi atanır daha sonra teslim tarihlerine göre sıralanarak üretime o şekilde alınırlar. Genellikle, teslim tarihi atama müsait kapasiteye bağlı olduğundan sıralama yaklaşımları, hangi işlerin sıralandığına bağlı olduğundan daha duyarlıdır. Sıklıkla kullanılan 3 tip teslim tarihi atama kuralı vardır. $\mathrm{Bu}$ kurallar ortak teslim tarihi (common due date - con), eşit aralık (equal slack - slk), toplam iş (total work - twk) olarak isimlendirilmişlerdir (Kaminsky ve Hochbaum, 2004).

Teslim tarihi problemiyle ilgili literatürde yapılan ilk çalışma olarak 1967 yılında Conway ve arkadaşlarının teslim tarihlerini tahmin etmek için iş akış sürelerini tahmin etmek amacıyla geliştirdikleri metot ön plana çıkmaktadır (Conway ve ark, 1967). Bir sipariş karışımı içerisinden en uygun olanları seçmek amacıyla yapılan çalışma Senju ve Toyoda tarafından 1968 yılında doğrusal programlama metodu kullanılarak gerçekleştirilmiştir. Senju ve Toyoda ilgili çalışmalarında sipariş tekliflerini sıralamak için sıra ölçekleri geliştirerek kısıtlayıcı koşullar altında 60 aday sipariş teklifi için örnek hesaplama adımlarını göstermiş̧lerdir (Senju ve Toyoda, 1968).

Vig ve Dooley 1991'de teslim tarihi atamayla ilgili son araştırmalarda halen temel alınarak kullanılan birçok yöntem düşünmüştür. Araştırmacılar çalışmalarında teslim tarihi atamak için toplam iş miktarı, işlem sayısı, sıradaki işlerin sayısı ve son işlerin akış zamanından elde edilen işlem akış süresi gibi yöntemleri kullanır (Vig ve Dooley, 1991). Wein ve Chevalier 
(1992) teslim tarihi müzakerelerini modelleyerek çalışmalarında, kısmi bir gecikme yüzdesi sınırlamasıyla ortalama teslim sürelerini minimize etmeyi hedeflemişlerdir. Wein ve Chevalier, atölye durumu, iş serbest bırakma tarihi, iş türü, sıralama ve serbest bırakma kurallarını dikkate alan bir tarih belirleme yönteminin, bunu yapmayan bir yöntemden üstün olduğunu savunmaktadır (Wein ve Chevalier, 1992). Philipoom tarafindan 1992 yılında yapılan çalışmada "order review / release (ORR)" yani "sipariş gözden geçirme / bırakma" kavramıyla karşılaşılmıştır. $\mathrm{Bu}$ zamana kadarki çalışmalarda gelen her siparişin kabul edileceği varsayıldığından siparişi reddetme durumları hiç göz önüne alınmamıştır. Philipoom, çalışmasında bir siparişi reddederek müşterinin başka tedarikçilerden siparişini temin etmesinin, müşteriye geç sipariş teslim etmekten daha iyi olduğunu öne sürmektedir. Çünkü gecikmesi olası bir siparişi kabul etmek, işletme darboğazında tıkanıklık olması durumunda teslimatı zamanında yapılacak bütün siparişleri de tehlikeye sokmaktadır (Philipoom, 1992).

1992 yılında yapılan başka bir çalışmada, $n$ tane yapılacak projeden bir alt küme seçerek projelerin uygulanmasında elde edilecek gelirin bugünkü değerini maksimize edecek ideal sıralamayı tanımlamak amaçlanmış ve bu amaca ulaşmak için problemin çözümünde polinom dinamik programlama metodu önerilmiştir (Gupta, 1992). 1995 yılında Aspvall'ın yaptığı çalışmada, Norveç Devleti'nin petrol rezervleri içerisinden belirli sayıdaki rezervi seçerek çeşitli nedenlerden dolayı belirli bir sırada petrol çıkarma ve günlük değeri en yüksek olan rezervi sıralama problemi için öne sürülen bir algoritma ile petrol rezervlerinin işlenme işi sıralanmıştır (Aspvall, 1995). Duenyas tarafından 1995 yılında, teslim tarihi ve fiyat konusunda farklı tercihleri olan birkaç müşteri sınıfi için siparişleri sıralayan ve teslim tarihi atayan bir çalışma yapılmıştır. Yapılan formül çalışması ile müşteri tercihlerini planlamada dikkate almanın dikkate almayan politikalardan oldukça üstün sonuçlar elde ettiği gösterilmiştir (Duenyas, 1995).

Müşterinin acil sipariş talebinde bulunması durumunda, işletmenin bu talebi tatmin etmenin diğer siparişlerde gecikmelere, kaynaklarda kısıtlamalara sebep olacağ sebeplerin işletmeye maliyeti bilinmemektedir. Bu tür durumlar için bir acil siparişi kabul etmenin maliyetini karışık tamsayı programlama modeli ile hesaplayan bir çalışma 1996 yılında $\mathrm{Wu}$ ve Chen tarafından yapılmıştır (Wu ve Chen, 1996). Easton ve Moodie, teslim süresi belirsizliğinin üzerinde az çalışılan bir konusu olan koşullu siparişlerdeki fiyatlandırma ve teslim tarihi kararlarını aynı anda optimize eden bir teknik sunmuştur (Easton ve Moodie, 1996). Bir işletmenin teslim tarihinde planlarını tutturma performansı, o işletmedeki çalışanların bireysel performanslarına da bağlıdır. 1998 yılında Philipoom ve Fry tarafından yapılan bir çalışmada, teslim tarihi performansını tehdit eden çalışanların düşük performansını arttırmak için çalışanların işlevsiz davranışlarını kontrol altına almayı sağlayacak iki yöntem önerilmiştir (Philipoom ve Fry, 1999). Müşteriler, üretim firmalarıyla hem ürün fiyatı hem de teslim süresi ile müzakere ederler. Moodie araştırmasında, 16 farklı pazar ve firma senaryoları için, farklı talep yönetim fiyatlandırma stratejilerini simülasyonla modelleme kullanarak farklı ücretlendirme politikalarını test etmenin ve kullanılabilir sonuçlar elde etmenin mümkün olduğunu göstermiştir (Moodie, 1999). Talep yönetimi ile ilgili birçok çalışması bulunan Moodie, 1999 yılında yaptığı bir diğer çalışma ile örnek bir işletme için çeşitli pazar senaryolarıyla farklı fiyat ve teslim tarihi teklif stratejilerini karşılaştırarak tüm teslim tarihi teklif stratejilerinin müzakereden daha faydalı olduğunu vurgulamıştır. Araştırma, fiyat gibi teslim tarihi üzerinden pazarlık yapmanın da oldukça faydalı olduğunu göstermiştir (Moodie, 1999).

Carr ve Duenyas, hem stoğa hem de siparişe üretim için gelen siparişlerin üretime alınmasında bir optimizasyon modeli geliştirmişlerdir (Carr ve Duenyas, 2000). Lewis ve Slotnick yaptığı çalışmalarında işletmenin birim iş başına elde edeceği net gelir ile siparişlerin 
gecikmesinden ödenecek cezaların maliyetini hesaplayarak karı maksimize edecek bir dinamik programlama algoritması sunmuştur (Lewis ve Slotnick, 2000). Nandi, 2000 yılında yaptığı doktora çalışmasında siparişe üretim işletmeleri için müşteri siparişlerini kabul veya reddetme kararlarını verecek ikisi algoritma, biri simülasyon tabanlı olmak üzere üç alternatif kural geliştirmiş ve bu kuralların nitel ve nicel performanslarını test etmek için analizler gerçekleştirmiştir (Nandi, 2000). Raaymakers ve arkadaşları yaptıkları çalışmada regresyona dayalı üretim kapasitesi tahmin modellerinin kalitesini karşılaştırmaktadır (Raaymakers ve ark, 2000). Duenyas ve Hopp, müşteri teslim süresi belirleme problemine sonlu kapasite ve sınırsız kapasite açısından yaklaşarak öncelikle sonlu kapasite için firmanın ilk gelen siparişi ürettiği durumu göz önüne almıştır (Duenyas ve Hopp, 2001). Keskinocak ve arkadaşları ise "acil teklif" durumunu takdim ederek müşteri sipariş talebine verilecek fiyat tekliflerinde siparişin acilen talep edilmesi durumunda yani teslim süresi hassasiyeti olduğu durumlarda fiyatlandırma politikasının değişerek yüksek gelir getirici siparişlerin acil olarak üretilebileceğini göstermişlerdir (Keskinocak ve ark., 2001).

Birbirini etkileyen süreçler olarak sipariş seçimi, çizelgeleme ve teslim süresi kararlarının belirli bir koordinasyonla verilerek teslim süresi esnekliğinin işletmenin karlılığını arttıracağını göstermeyi amaçlayan detaylı bir çalışma 2004 yılında Charnsirisakskul ve arkadaşları tarafından yapılmıştır. Sonuç olarak teslim süresi esnekliğinin siparişi kısmi yerine getirme esnekliğinden daha faydalı olduğu gösterilmiştir (Charnsirisakskul ve ark., 2004). Fiyat konusunu da teslim süresi belirleme, planlama ve sipariş seçme gibi üretim kararlarına dahil eden Charnsirisakskul ve arkadaşları, başka bir çalışmasında farklı müşterilere aynı ürün için aynı fiyatı veya farklı fiyatı teklif etme durumunu incelemiştir. Araştırmacılar, müşterilerin beklentilerine, coğrafi farklılıklarına göre aynı ürünler için farklı fiyatlandırmaya tabi tutulabileceğini vurgulayarak talep, fiyat, kapasite, teslim süresi gibi kısıtlar altında maksimum işletme karına ulaşabilmek için karışık tamsayı programlama kullanarak bir formül geliştirmişlerdir (Charnsirisakskul ve ark., 2006).

Nandi ve Rogers, siparişlerle ilgili kabul veya ret kararını vermek ve üretim sistemini daha iyi kontrol etmek için simülasyon tabanlı bir sipariş kabul kural modeli geliştirmiştir (Nandi ve Rogers, 2004). Bu simülasyon ile satış pazarlama biriminin gelecekteki siparişleri girmesine izin verilmediğinden ve işlem sürelerinin tahmini olarak girildiğinden dolayı simülasyon bazen uygunsuz kabul-ret kararlarını da vererek olası hatalara da neden olmuştur (Nandi ve Rogers, 2004). Slotnick ve Morton, 2005 yılında kapasitenin sinırlı olduğu, müşterinin geç teslimlerden indirim aldığı ama erken teslimin ne cezalandırıldığı ne de ödüllendirildiği durumlardaki sipariş kabul kararlarını çalışmışlardır (Slotnick ve Morton, 2005). Siparişlerin teslim tarihi problemleriyle ilgili literatürde yer alan çalışmaların neredeyse tamamı sayısal analizler ve formülizasyon çalışmalarından oluşmaktadır. 2006 yılında Zorzini ve arkadaşları, 15 İtalyan şirketini temel alarak bu şirketlerdeki yöneticilerin, teslim tarihi belirlemede kullandıkları kararları prosedürel olarak tanımlayıp bu alanda genel bir çerçeve oluşturmayı hedeflemiştir (Zorzini ve ark., 2006). Zorzini ve arkadaşları deneysel çalışmalardan elde ettiği bulgulardan yola çıkarak teslim tarihinin "sabit" veya "pazarlık edilebilir" durumuna ve siparişlerin "hızlı" veya "yavaş" durumuna bağlı olarak teslim tarihi teklifi için modellerinde "pazarlık edilebilir teslim tarihi - hızlı sipariş", "pazarlık edilebilir teslim tarihi - yavaş sipariş", "sabit teslim tarihi" gibi farklı prosedürler önermektedirler Nihai olarak araştırmacılar 15 İtalyan şirket örnekleminde kapasite ve teslimat süresi yönetimini destekleyen yönetsel uygulamaları araştırıp deneysel sonuçlara dayanarak seçilen vakalar için teslim tarihlerini belirleme karar sürecini resmileştirecek bir model önermiştir (Zorzini ve ark., 2006). 
Ebadian'ın çalışmasında da Zorzini ve arkadaşlarının çalışmasında olduğu gibi gelen siparişlerin teslim tarihi ya sabittir ya da müzakere edilebilirdir. Araştırmacının önerdiği yapıda gelen siparişler, önemlerine göre iki önemli kriter olan kar ve pazar payı göz önünde bulundurularak iki gruba ayrılmıştır. Bu gruplar; önemli derecede kar sağlayabilen ve şirketin pazar payını artırabilen yüksek öncelikli siparişler ve sadece şirketin pazar payını artırabilecek düşük öncelikli siparişler şeklindedir. Ebadian'ın önerisi, sadece düşük öncelikli siparişler ertelenebilir veya yüksek öncelikli siparişler zamanında teslim edilmelidir kuralına dayanır (Ebadian, 2007). 2007 yılında Lee tarafından yapılan bir araştırmada tek makineli bir üretim ortamında dış kaynak kullanımının varsayıldığı durumlara dikkat çekilmiş̧ir. Bunun için dış kaynak maliyetinin ağırlıklı toplamını minimize etmek ve üretim planlama ölçüsünü dış kaynak bütçesine bağlı toplam tamamlanma süresi ile göstermek amaciyla bu problemin çözüm özellikleri karakterize edilerek bir algoritma geliştirilmiş ve geliştirilen algoritmanın performansını değerlendirmek için sayısal deneylerle analizler gerçekleştirilmiştir (Lee, 2007). Yang tarafindan aynı yılda Lee ile benzer şekilde tek makineli bir üretim ortamı için aday siparişlerin kabul ya da ret edildiği bir planlama kapsamında gecikme maliyetleri ve maliyet olarak işleme süreleri kapsamında karlılığı maksimize etmeyi araştırmıştır (Yang, 2007).

Gharehgozli ve arkadaşları, 2008 yılında yaptıkları çalışmalarında siparişlerin kabulünde ve sıralanmasında etkili olabilecek kriterleri tanımlamaya çalışarak iki fazlı bir karar modeli önermişlerdir (Gharehgozli ve ark., 2008). Önerilen karar modelinde, ilk fazda teslim tarihlerine göre gelen siparişlerin kabul veya ret edilmesi için siparişlerin işlem bitiş tarihi, en erken çıkarma tarihi ve son çıkış tarihi hesaplanır. Buna göre değerlendirilip sonraki fazda üretim kapasitesi baz alınarak birinci fazda kabul edilen siparişlerin kabul veya reddi için analitik hiyerarşi prosesi (ahp) ve topsis (Technique for Order Preference by Similarity to Ideal Solution) yöntemlerini içeren yeni hibrit bir metodoloji sunulmuştur. (Gharehgozli ve ark., 2008). Gordon ve Strusevich, 2008 yllinda tek makineli planlama ve teslim tarihi probleminin çözümü için önerdiği amaç fonksiyonunda, bir siparişin teslim tarihini değiştirmenin maliyetini ve kendi teslim tarihinde tamamlanamayan işlerin toplam maliyetini minimize etmeyi önermiştir. Bu amaçla iki popüler teslim tarihi atama metodu olan CON ve SLK ile birlikte polinom - zamanlı bir dinamik programlama algoritmasını sunmuştur (Gordon ve Strusevich, 2008). Deng ve arkadaşları daha iyi gelir firsatları yakalamak amacıyla stokastik olan talebi yönetmek için gelir bazlı bir kapasite yönetim modeli önermiş̧ir (Deng ve ark., 2008). Bu çalışmada önerilen model, hizmet ve imalat ortamlarında yüksek gelir getirici pazar segmentleri için kapasiteyi paylaştıran sipariş kabul politikaları oluşturur (Deng ve ark., 2008). Pibernik ve Yadav, siparişe üretim yapan firmalarda gelen siparişlerde yüksek öncelikli müşteriye ait olma durumunu göz önünde bulundurarak, yüksek öncelikli ve normal olmak üzere 2 sınıf müşteri grubundan rastgele gelen sipariş taleplerine değinmişlerdir (Pibernik ve Yadav, 2008). Araştırmanın analiz sonuçlarına bakıldığında, önerilen kapasite rezerv metodunun sadece yüksek öncelikli müşteri taleplerinin karşılanmasını değil aynı zamanda işletmenin genel kapasite kullanım oranını arttırdığı da belirtilmiştir (Pibernik ve Yadav, 2008). 2008 yılında yapılmış başka bir çalışma olan Rom ve Slotnick'in çalışmalarında sipariş kabul problemini çözmek için kar maksimizasyonuna dayalı amaç fonksiyonunda siparişlerden elde edilen toplam gelirden toplam gecikme maliyetinin farkını alarak işletmenin nasıl daha karlı duruma geçebileceğine dikkat çekilmiştir (Rom ve Slotnick, 2008). Chen ve arkadaşları, 2009 yılında siparişe üretim işletmelerinin kapasite planlama problemlerine değinirken, çalışmalarında normal süre, fazla mesai ve dış kaynak kullanımını da dikkate alarak maksimal kapasite kullanımı ile optimum faaliyet karı arasında bir karşıtlık olduğunu göstermişlerdir (Chen ve ark., 2009). 
Bazı işletmeler hem stoka hem siparişe üretim yaparlar. Böyle hibrit üretim ortamlarında sipariş kabul-ret kararlarını vermek için Kalantari ve arkadaşları tarafından 5 aşamalı bir karar destek modeli geliştirilmiştir (Kalantari ve ark., 2010). Oğuz ve arkadaşları, siparişlerin giriş̧ tarihi, bitiş tarihi, teslim tarihi, işleme süresi, sıraya bağl kurulum süresi ve gelirleriyle tanımlandığı tek makineli bir üretim ortamı için sipariş kabul ve planlama kararlarını çalışmıştır (Oğuz ve ark., 2010). Patil tarafından 2010 yılında yapılan çalışmada önceki planlama çalışmalarında müşteri memnuniyeti ilkelerinin yeterince dikkate alınmadığı vurgulanarak, "Müşteri memnuniyetine odaklı dinamik teslim tarihi teklifi politikasının" müşteri memnuniyeti ve net kar açısından oldukça önemli olduğu ve bu politikanın literatürde daha önce test edilen diğer teslim tarihi politikalarına göre oldukça başarılı olduğu simülasyon deneyleri ile belirtilmiştir (Patil, 2010). Foreest ve arkadaşları tarafından "Özelleştirilmiş̧ Stokastik Lot Planlama Problemi” için yüksek darboğaz kullanımını başaracak birçok müşteri siparişi kabul politikası geliştirilmiş ve analiz edilmiştir. (Van Foreest ve ark., 2010). 2011 y1lında Yoon ve Nof isimli araştırmacılar gelen siparişlerin durumuna göre kapasiteyi dalgalandırarak söz verilen mevcut siparişlerin teslim tarihlerini değiştirmeden sadece kapasiteyi arttırarak yeni gelen siparişleri kabul etmek için bir kısım metotlar önermiş̧tir (Yoon ve Nof, 2011). Chaharsooghi ve arkadaşlarının çalışmasında sınırlı bir üretim kapasitesi ve stokastik talep fonksiyonu altında çok periyotlu siparişe üretim ortamlarında; dinamik olarak fiyat, teslim süresi seçimi ve müşterilerin gruplandırılmasındaki esnekliğin rolüne dikkat çekilmiştir (Chaharsooghi ve ark., 2011). Buna göre işletmelerin ürünleri için izleyeceği değişken fiyatlandırma ve esnek teslim tarihi kararları ile performanslarını arttırılabileceği öne sürülmektedir (Chaharsooghi ve ark., 2011). Yeni bir yaklaşım olarak, "Söz vermek için karlı" yaklaşımı ve karışık tamsayı programlama ile sistem dinamiklerinin simülasyonunu birleştiren yeni bir hibrit karar destek sistemini sunan Khatai ve arkadaşlarına göre; sunulan modelin çıktıları, daha fazla siparişi yerine getirmenin fiilen şirketin kârını düşürdügünü ve ürün satış fiyatını ayarlamayı gerektirdiğini göstermektedir (Khatai ve ark., 2011). Bir şirketin planlı siparişlerinin yanı sıra talep dışı gelebilecek potansiyel siparişleri de olabilir. Böyle bir ortam için talep dışı gelebilecek potansiyel siparişlerden oluşan bir havuzu olan tek makineli üretim ortamları için sipariş kabul ve planlama çalışmaları Nobibon ve Leus tarafindan genelleştirilmiştir (Nobibon ve Leus, 2011).

Germs ve Foreest tarafindan 2012 yılında yapılan bir model çalışmasında ise, teslim tarihi problemi için müşteri siparişleri; birlikte üretilebilecek, birbirine bağımlı olan ürün grupları şeklinde gruplanarak, üretim miktarının (lot büyüklüğünün) kapasiteyi en iyi kullanabilecek şekilde hesaplanarak üretime hazırlık süresindeki kayıpları en aza indirmeyi amaçlanmış, aynı sipariş - ürün ailesi için ortak bir teslim tarihi tavsiye edilmiştir (Germs ve Foreest, 2012). Lu ve arkadaşları tarafindan 2013 yılında yapılan bir çalışmada öne sürülen algoritma sayesinde, müşterinin sipariş sıralamasındaki belirsizliğin modellenmesini ve birden fazla farklı siparişin ayrıntılı sıralama kararı birleşik bir çerçevede sunulur (Lu ve ark., 2013). Guhlich ve arkadaşları tarafından 2015 yılında yapılan çalışmada, gelir yönetiminde kar maksimizasyonu sağlayabilmek amacıyla, siparişe göre montaj yapan işletmeler için bir talep yönetim modeli öne sürülmektedir (Guhlich ve ark., 2015). Kabul edilen siparişlere teslim zamanı verecek olasılık tabanlı bir program olan "Stokastik dinamik program (SDP)" yapılmıştır. SDP ile her gelen sipariş için karı maksimize edecek bir teslim tarihi aranmaktadır. Karlı bulunan siparişler kendi teslim tarihleri ile kabul edilmekte, karlı bulunmayan siparişler ise reddedilmektedir (Guhlich ve ark., 2015).

Mor ve arkadaşları literatürdeki tek makineli planlama çalışmalarından farklı olarak işe bağlı teslim süresi için teslim tarihi atama problemini çalışmışlardır. Çalışmalarında her iş için erken maliyet, gecikme maliyeti ve teslim tarihinin teslimat süresinden daha gecikmesi 
durumunda doğacak geciktirme maliyeti olmak üzere üç maliyet bileşenini kullanmıştır. Yapılan formül çalışmasında amaç, işleri planlarken tüm sıralı işler arasındaki azami maliyetin en aza indirilerek teslim tarihi atamaktır (Mor ve ark., 2013). Aleksandar, siralı iki makinedeki işlerin akışı için az bir gecikme ile ortak teslim tarihi belirleme problemi üzerinde ikili ağaç veri yapısı yöntemini kullanarak bir çalışma yapmıştır (Ilić, 2015). Jagan ve arkadaşları yine tek makineli üretim ortamı için bir miktar boşta kalma süresi ekleyerek tüm işlerin ceza değerlerini en iyi duruma getirmek için bir çalışma yapmışlardır. Farklı planlama periyotları için yapılan çalışmada en uzun işlem süresinin ilk önce üretilmesi yönteminin en az ceza değeri elde ettiği sonucuna varmışlardır (Jagan ve ark., 2015). Demir ve arkadaşları tarafından süreç planlama ve zamanlama ile SLK teslim tarihi yöntemini genetik algoritma ve rastgele arama teknikleri ile entegre ederek yaptıkları çalışmada erken ve geç kalan teslim tarihlerinin cezalandırılması varsayılmıştır. Yapılan çalışmanın neticesinde genetik algoritma çözümünün diğer çözümlerden daha iyi performans gösterdiği vurgulanmıştır (Demir ve ark., 2015).

Low ve arkadaşları tek makine planlama ortamında planlı bakım periyotlarını dikkate alarak ortak bir teslim tarihi için işlerin tamamlanma zamanlarının mutlak sapmalarını en aza indirgemeyi amaçlayan bir çalışma yapmıştır. Yapılan çalışmada problem öncelikle matematiksel olarak karışık tamsayı doğrusal programlama yöntemi ile formüle edilerek çözülmüştür (Low ve ark., 2015). Canıyılmaz ve arkadaşları tarafından yapılan çalışmada belirli makine kısıtlamaları ile belirli bitiş tarihi kısıtlamalarını göz önünde bulundurarak iş sırasına bağlı kurulum süresi özelliği kullanılarak toplam gecikmeyi minimuma indirmek amaçlanmıştır. Gerçek bir fabrika verisi ile yapılan çalışmada yapay arı koloni algoritması ve genetik algoritma entegre edilerek kullanılmış olup yapay arı koloni algoritması genetik algoritmadan daha performanslı bulunmuştur (Canıyılmaz ve ark., 2015).

Çakar ve arkadaşları ise tek makineli ortamda çift teslim tarihi ile geciken işlerde geçen süreye göre iki farklı gecikme maliyetini uygulayarak toplam ağırlıklı gecikme maliyetini azaltmaya çalışmışlardır. Yapılan çalışmada toplam ağırlıklı gecikmeyi azaltmak için Nörobaskınlık kuralı yöntemi önerilmiştir. Nöro-baskınlık kuralını elde etmek için yapay sinir ağı ile 12.000 veri öğesi kullanılıp farklı 15.000 veri üzerinde test işlemleri yapılmıştır (Çakar ve ark., 2015). Baker ve Trietsch, sıralanan işlerin geç kalmaması ile teslim tarihlerinin gecikmemesini dengelemek amacıyla stokastik tek makine modeli için formül çalışması yapmışlardır (Baher ve Trietsch, 2015). 2016 yılında yapılan bir çalışmada satış pazarlama, üretim planlama ve nakliye departmanlarının yaptığı işler olan teslim tarihi, üretim planlaması ve teslimat dağıtım planlaması aşamalarının tek makineli ortamda gecikme ile ilgili maliyetlerin en aza indirilmesi sorunu araştırılmıştır. Problemin çözümünde formüller karışık tamsayı doğrusal olmayan programlama ve karışık tamsayılı programlama yöntemleri kullanılarak çözülmüş̧ür (Assarzadegan ve Rasti Barzoki, 2016). Shabtay ve arkadaşları tarafından 2016 yılında tek makine planlama ortamında toplam ağırlıklı iş sayısı ve teslim tarihi atama maliyetini en aza indirgemek amacıyla polinom algoritması teknikleri kullanılarak bir yaklaşım şeması önerilmiştir (Shabtay ve ark., 2016). Schäfer ve arkadaşları, dört gerçek üretici firmanın geribildirim verileri üzerinde istatistiksel hesaplamalar yaparak şirketlerin kullandığı teslim tarihi performans kriterleri olan gecikme, göreli gecikme, zamanlama güvenirliği gibi özelliklerin birbirleri arasındaki ilişkilerini analiz etmiştir (Schäfer ve ark., 2016).

Demir ve arkadaşları entegre süreç planlama ve çizelgeleme ve teslim tarihi atama problemi üzerinde çalışmışlardır. Bu konuda literatürde yapılan ilk çalışmadır. Çünkü süreç planlamanın çıktısı çizelgeleme işleminin girdisi olmakta, çizelgeleme işlemlerinin çıtısı ise teslim tarihi olarak karşımıza gelmektedir. Araştırmacılar çalışmalarında rastgele arama, hibrit arama ve genetik algoritma ile arama yöntemlerini kullanmış olup en iyi çözüm kombinasyonunu hibrit aramanın verdiğini vurgulamışlardır (Demir ve ark., 2016). Aynı 
problem için Demir ve Erden tarafından yapılan başka bir çalışmada ise genetik algoritmanın en iyi çözümü sunduğu vurgulanmıştır (Demir ve Erden, 2017). Samarghandi ve Behroozi tarafından geliştirilen bir algoritma ile atölye çizelgeleme problemi üzerine çalışılmıştır. Yapılan çalışmada her işin belirlenmiş bir teslim tarihi zorunlu kısıt olarak kullanılıp ardışık işler arasında bekleme süresinin olmadığı kabul edilerek hesaplamalar yapılmıștır. Geliştirilen algoritmanın matematiksel modellerden çok daha hızlı olduğu test problemleri çözümüyle gösterilmiştir (Samarghandi ve Behroozi, 2016). Kuroda tarafından yapılan çalışmada ise teslim tarihi tahmin yöntemleri ile müşterinin sabit olmayan ürün özelliklerine göre talep ettiği siparişler üzerinde araştırma yapılarak ürün tasarımı ve üretimin entegrasyonu ile teslim tarihi probleminin yakından ilişkili olduğu vurgulanmıştır. Çalışmanın sonucunda müşteri gereksinimlerini karşılamak ve daha verimli bir ürün elde etmek için ürün tasarım birimi ile üretim birimi arasında bilgi paylaşımının gerekliliği doğrulanmıştır (Kuroda, 2016). Ortak bir teslim tarihi ile toplam erken gecikmeyi en aza indirmek amaciyla tek makineli ortam için yapılan bir çalışmada karışık tamsayı doğrusal programlama ve dinamik programlama yöntemleri büyük bir veri seti üzerinde kullanılarak test edilmiştir. Low ve arkadaşları tarafından yapılan bu çalışmada dinamik programlama yönteminin ideal çözümler elde etmede daha az bellek gereksinimi ile daha etkili olduğu vurgulanmıştır (Low ve ark., 2016).

Li ve Chen tarafından 2017 yılında geliştirilen polinom zaman algoritması ile tek makineli planlama ortamında teslim tarihi atama problemine bir çözüm önerilmektedir. Yapılan çalışmada ortak teslim tarihi ve iş planını belirlemek ve teslim tarihi atama maliyeti, toplam erken cezalarını içeren bir maliyet ceza fonksiyonunu minimize etmek amaçlanmıştır (Li ve Chen, 2017). Yeni gelen bir siparişin mevcut iş yüküne ekleneceği dinamik akışlı bir fabrika ortamı için toplu iş planlama problemi Nurainun ve arkadaşları tarafından çalışılmıştır. Çalışmadaki karar mekanizması yeni eklenen işin toplam maliyetini mevcut iş çizelgesiyle karşılaştırarak gerçekleştirir. Toplam maliyeti en aza indirmek için parti büyüklügüünü de bulmak için bir algoritma geliştirilerek çözümde karışık tamsayı doğrusal olmayan programlama yöntemi kullanılmıştır (Nurainun ve ark., 2016). Ortak bir teslim tarihi için çok sayıda ürün üreten bir makinedeki seri üretim ve arıza durumu için bakım planlamasının entegre düşünüldüğü bir problemde üretim süresinin uzamasına bağlı olarak stok maliyeti ve bakım maliyetini dengelemek amacıyla bir çalışma yapılmıştır. Yapılan çalışmadaki amaç fonksiyonu stok maliyeti, kurulum maliyeti, önleyici ve düzeltici bakım maliyeti ve yeniden işleme maliyetini kapsayan toplam maliyeti minimize etmektir (Zahedi ve ark., 2016). Zhao tarafindan yapılan bir çalışmada gecikmiş iş sayısını ve teslim tarihi maliyetini içeren bir maliyet fonksiyonunu minimize etmek amaciyla dinamik programlama algoritması ve polinom zamanlı bir yaklaşım şeması önerilmiştir (Zhao, 2016). Lin ve arkadaşları; makine sayısı, bakım, kısmi ve beklenmedik arıza durumları için bir üretim ortamı tasarlayarak bu ortamda her aşamadaki kapasiteyi stokastik olarak kabul eden bir yaklaşım önermiştir. Araştırmacılar, önerilen yaklaşımın belirli bir teslim tarihi için piyasa koşullarını karşılayabilmesini ise çalışmada "güvenilirlik" kavramını tanımlayarak çalışmanın uygulama aşamasında kiremit ve ayakkabı üretim sistemi için tahmini tarih aralıklarını ve önerilen algoritmanın verimliliğini sunmuşlardır (Lin ve ark., 2017). Drwal ise yaptığı çalışmada tek makina çizelgeleme problemi için teslim tarihlerinin tam olarak bilinmediği durumlarda geç kalan işılerin ağırlıklı sayısını minimize etmeyi amaçlamıştır. Çalışmada işlerin ağırlıkları eşit olduğu varsayılarak hesaplamalarda karışık tamsayılı bir doğrusal programlama formülü kullanılmıştır (Drwal, 2017). Lödding ve Piontek ise en erken bitiş süresine göre siparişleri sıralama etkinliğini analiz etmiştir. Çalışmada önerilen basit bir model ile işlerdeki gecikmenin erken bitiş süresine göre sıralama vasıtasıyla telafi edilip edilemeyeceği gösterilmiştir (Lödding ve Piontek, 2017). 


\section{3. İnovatif ve Yeni Bir Pazarlama İs Süreci}

Siparişe üretim yapan işletmelerin müşteri siparişlerini elde tutabilmek ve kapasitelerini doldurabilmek amacıyla karlılıklarını sürdürebilmesi, işletmenin pazarlama biriminde görev yapan karar verici yöneticilerin ve pazarlama iş sürecinin performansına bağlıdır. Bir siparişin kesinleştirilmesi müşteri ile fiyat, ödeme tarihi, teslim tarihi, teslimat işlemleri gibi birçok konuda mutabakata varmayı gerektirdiğinden pazarlama birimi yöneticileri işletmenin üretim planlamasına dahil olarak ilgili üretim birimleriyle koordineli çalışmalıdır. Çünkü müşteriler çoğu zaman ürünlerini erken bir tarihte teslim almak ister ancak işletmede var olan mevcut üretim yükü değişmeyeceğinden belirli bir plan dahilinde ilerleyen üretim sürecine müdahalede bulunma, çeşitli zorlukları da beraberinde getirecektir.

Kurumsal kaynak planlaması (enterprise resource planning - erp) yazılımları ile ham maddenin işletmeye girişinden ürünün müşteriye teslimatına kadar her iş sürecini ilgili yazılım otomasyonları ile takip eden yüksek enformasyon altyapısına sahip işletmelerde, pazarlama birimleri gelen siparişler için ürünü müşteriye verebileceği en erken tarihi hesaplayarak bir teklifte bulunurlar. Dünya çapında yaygın olarak kullanılan SAP, Microsoft Ax, Oracle gibi global ölçekli erp sistemlerinde bile teslim tarihleri üzerinde simülasyon yapma imkânı bulunmamaktadır. Sadece ileriye veya geriye planlama fonksiyonları çalıştırılarak ya ürünün mevcut kısitlarda en erken ne zaman teslim edilebileceği hesaplanmakta, ya da belirli bir tarihte ilgili ürünü teslim edebilmek için gereken ham madde temininin ne zaman başlaması gerektiği bilgisini sunmaktadır.

Gelişen enformasyon sistemleri ve zorlaşan rekabet ortamı içerisinde işletmeler karlılıklarını arttırmak ve pazar paylarını koruyabilmek için rekabet avantajlarını arttırma yollarına gitmelidir. Bu yollar da karar desteği duyulan işs süreçleri için inovatif dönüşümler ile süreçlerin iyileştirilmesiyle açılmaktadır. Çalışmada bahsi geçen teslim tarihi problemi için pazarlama birimleri gelen siparişi olduğu gibi işletme havuzuna atarak bir tarih vermek yerine pazarlama süreçlerinde inovatif dönüşümler yaparak siparişleri bir havuzda toplamalı ve mevcut siparişlere bir tarih verip kesinleştirmeden önce haftalık, aylık veya istenilen herhangi bir periyot için teslim tarihlerini ilgili siparişleri çeşitli kriterlere göre sıralayarak işletmenin maliyet veya karlılık durumlarını araştırmalı, bu araştırma için karar destek sistemleri veya simülasyon programları kullanmalıdır. Bu şekilde pazarlama birimlerinde gelen bir sipariş doğrudan kabul edilmek yerine siparişler önce bir sıralama işlemine tabi tutularak işletmenin amaçları doğrultusunda performansını arttıracak kriterlere göre elde edilen sıralama sonuçlarıyla siparişlere bir tarih verilmesi hem rekabet ortamında işletmenin elini güçlendirecek hem farklı kriterlere göre sıralanan siparişleri birçok kriter yönünden optimize etmiş olacaktır. $\mathrm{Bu}$ noktada işletmelerin ihtiyacı, dönüştürdükleri pazarlama süreçlerini ihtiyaçlarına cevap verecek pazarlama bilgi sistemleri ve karar destek sistemleri ile destekleyerek etkili karar vermeyi sağlamaktır.

\section{Sipariş Sıralama İçin Doğrusal Karar Modeli Önerisi}

Pazarlama birimleri için inovatif bir dönüşüm önerisinde bulunurken bu dönüşüm için işletmenin ihtiyaçları ve amaçları doğrultusunda çeşitli karar modellerini kullanarak üretim planlama aşamasına geçmeden önce biriken sipariş kayıtlarının belirli kriterlere göre sıralanması gerekmektedir. Bu sıralama işlemi, müşterileri önceliklendirmede veya acil sipariş kavramını karşılamak amacıyla reddedilmeyecek bir siparişi araya sıkıştırmada oldukça verimli olabileceği gibi aynı zamanda işletmenin üretim planlama, üretim ve pazarlama birimleri arasında da bir koordinasyon sağlamış olacaktır. 
Yapılan çalışma ile şimdiye kadar literatürde teslim tarihi problemine karşı yapılan sayısal çözümler gözden geçirilmiştir. Oysa son kullanıcı olarak pazarlama yöneticilerine veya üretim planlama sorumlularına hitap edecek, problemin çözümünü gerçek hayata uyarlayabilecek bir çalışma bulunmamaktadır. Bu çalışmada literatürde daha önce yapılmış formül çalışmalarından farklı olarak işletmeler için örnek bir karar modeli önerisi getirilerek modelin Excel gibi basit ve yaygın kullanılabilecek bir programla bile kullanılabileceği vurgulanmaktadır.

İşletmeye gelen siparişler müşteri, ürün ve sipariş verilerinden yola çıkılarak çeşitli kriterler tarafindan incelenmelidir. Müşteri açısından müşteri ile çalışılan yıl sayısı, müşterinin yıllık cirosu, müşterinin yıllık sipariş miktarı kriterleri öne çıkmaktadır.

Sipariş başlığında ise siparişin ödeme vadesi, siparişin tutarı, sipariş için varsa talep edilen bir teslim tarihi gibi kriterler siparişleri sıralamada bir işletme için göz önünde bulundurulabilecek kriterlerdir. Çünkü yüksek tutarlı bir sipariş işletmenin amaçları doğrultusunda daha ön sıralarda üretilip teslim edilebilir. Başka bir yönden bakılacak olursa çek yerine nakit ödemeli bir sipariş işletmenin nakit akışını arttırmak amacıyla önceliklendirilebilmektedir.

Ürün açısından bakıldığında ürünün üretim süresi, üretime geçmeden önce harcanan hazırlık süresi, ürünün diğer müşteriler tarafından ne kadar ilgi gördüğü (toplam üretime oranı), üründen elde edilecek kar veya birim ürün üretiminin maliyeti gibi kriterler öne çıkmaktadır. Birçok müşteriye hitap eden ürünlerden oluşan siparişler önceliklendirilebilir, üretim süresi en kısa veya en uzun sürecek ürünler siparişleri sıralarken daha ön sırada işleme alınabilir, iki üretim arasında üretime hazırlık süresi açısından en az zaman kaybedilecek ürünler ardış1k olarak üretilebilir.

Müşteri, sipariş ve ürün açısından bu kriterlerden bahsettikten sonra bütün bu kriterleri dengede tutacak çok kriterli bir karar modeli önermekteyiz. Önerilen karar modeli ile uzun yıllar çalışılan veya yüksek ciroya sahip müşteriler önceliklendirilmekle birlikte, sipariş tutarı çok yüksek olan siparişler de sıralamada kendini ön plana getirebilmektedir. Önerilen karar modeli şu şekildedir:

Müşterilerin yıllık cirosu, yıllık sipariş miktarı ve müşteri ile çalışılan yıl kriterleri müşteri açısından karar modelinde (1) nolu denklemde gösterildiği gibi sipariş sıralama kriteri olarak yer alacaktır.

$\mathrm{M}(\mathrm{i})=\mathrm{W}_{\mathrm{m} 1}$. YıllıkCiro $+\mathrm{W}_{\mathrm{m} 2 .}$.Y.llıkSiparişMiktarı $+\mathrm{W}_{\mathrm{m} 3}$.Çalışı1lanYı1Sayısı

Üretilen ürünler için (2) nolu denklemde gösterilen; birim miktar üründen elde edilen kar, birim miktar ürünün üretim süresi, üretime hazırlık süresi, ürünün yıllık satış miktarı ve üretim sırasındaki eldeki stok miktarı kriterleri önerilmektedir.

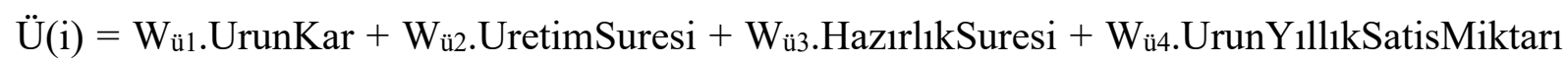
$+\mathrm{Wu}_{\mathrm{us} . S t o k M i k t a r 1}$

Sipariş açısından ise siparişten işletmenin elde edeceği toplam gelir olarak siparişin toplam tutarı ve siparişin ödeme vadesi kriterleri (3) nolu denklemdeki gibi kullanılmaktadır. 
(1), (2) ve (3) nolu denklemlerde kullanılan W çarpanları her bir kriterin model içerisindeki ağırlık katsayılarını ifade etmektedir ve her model için ilgili W değerleri toplamı 1'e eşit olmalıdır.

$\mathrm{W}_{1}+\mathrm{W}_{2}+\ldots . \mathrm{W}_{\mathrm{n}}=1$

Modelin ana fonksiyonu olarak (5) nolu denklemde gösterilen F fonksiyonu ise maksimize edilecek amaç fonksiyonudur. Bu fonksiyon; müşteri, ürün ve sipariş kriterlerinin ağırlıklı toplamından oluşan doğrusal bir fonksiyondur. W ağırlık katsayıları yine (4) numaralı denklemde belirtildiği gibi toplam 1 olacak şekilde kullanılmalıdır.

$\mathrm{F}(\mathrm{i})=\mathrm{W}_{1} \cdot \mathrm{M}(\mathrm{i})+\mathrm{W}_{2} . \ddot{\mathrm{U}}(\mathrm{i})+\mathrm{W}_{3} \cdot \mathrm{S}(\mathrm{i})$

Teslim tarihi problemi çözümü için gerçek hayatta siparişleri sıralamada bir işletme için kullanılabilecek kriterler belirlenerek ilk defa problem çok kriterli bir karar modeli olarak tasarlanmıştır. Problemin çözümü için müşteri, ürün ve sipariş verileri yukarıdaki formüller kullanılarak her bir sipariş kaydı için $i$ bir sipariş kaydını belirtmek üzere M(i), Ü(i) ve S(i) değerleri hesaplanarak bunların ağırlıklı toplamı olan F(i) değerleri hesaplanır. Fonksiyonların hesaplamaları yapılırken farklı ölçü birimine ait kriterler kendi içerisinde maksimum değerlerine bölünerek tüm kriterler 0 ile 1 arasında değerlere normalleştirilir. Bu normalizasyon işleminden sonra asıl karar matrisleri elde edilmiş olur. Bu sayede farklı ölçü birimi ve büyüklükteki kriterler kendi içerisinde normalleştirilerek her kriter aynı ölçüt birimi ve aralıkta ifade edilmiş olur. Birçok kriterin ağırlıklı olarak etki ettiği F(i) değeri, son durumda her bir sipariş için hesaplandıktan sonra siparişleri sıralamada kullanılacak ana veridir. Siparişler F(i) değerlerine göre büyükten küçüğe doğru sıralanır ve bu sıralama siparişlerin üretime alınma sirası olarak kullanılır.

Burada kullanılan W ağırlık katsayıları işletme yöneticilerinin tecrübe ve öngörülerine göre \% cinsinden verilebileceği gibi çeşitli uzman görüşleri araştırılarak uzmanlara bu kriterlerin ağırlıkları için önerecekleri değerlerin ortalamalarını kullanacak şekilde de verilebilir. Dikkat edilmesi gereken nokta yukarıda bahsedilen kriterlerden bazılarının maksimizasyonu bazılarının minimizasyonu gerekebilir. Örneğin bir işletme işlem süresi en uzun olan ürünü üretmeyi önceliklendirmek istiyorsa sipariş kayıtları içerisinde en uzun işlem süresine sahip olan kaydı maksimum değer noktası olarak belirlemeli, en kısa işlem süresini önceliklendirmek istiyor ise tam tersi olarak en erken sürede üretilecek ürün için minimum değer noktası olarak belirlemelidir. Kriterlerin birbirleriyle aynı ölçü biriminden karşılaştırılabilmesi için bu şekilde bir elektronik tablo ile normalizasyon işlemlerine tabii tutulmalıdır. 


\section{Sonuç}

Müşteri taleplerine göre yapılan siparişe üretimde teslim tarihinin belirlenmesi birçok farklı kriteri de göz önünde bulundurarak siparişleri sıralamayı, belirlenen bu sıralamaya göre üretim planına dahil ederek üretmeyi ve işletme kapasitesini bu üretim programına göre dizayn etmeyi gerektirir. Bu bağlamda teslim tarihi problemi birçok kritere bağlı olduğundan çok kriterli bir karar yapısı ile çözülmesi gereken problemlerdir. Önceki çalışmalara bakıldığında araştırmacılar probleme sadece belirli bir açıdan yaklaşarak örneğin sadece müşteri memnuniyeti, kapasite planlaması, gelir veya kar maksimizasyonu gibi amaçlarla yaklaşmıştır. Oysa problemin çözümünde bu değişkenlerin tamamını dikkate alacak karar modelleri kullanılarak işletmeler ihtiyaç duyacağı karar destek sistemleri ve simülasyon programları ile pazarlama süreçlerini iyileştirmelidir. Çünkü bir işletmenin yetenekleri ancak enformasyon sistemlerine yaptığ 1 yatırımlarla sınırlıdır. Yapılan bu çalışma ile siparişe üretim yapan işletmelerin karşılaştığ teslim tarihi probleminde literatürde bulunan çalışmalar derlenerek kapsamlı bir tarama ile bu alandaki araştırmacılar için bir kaynak oluşturulmuştur. Ayrıca pazarlama yönetimi için iş süreçlerinin yenilenmesi, inovatif dönüşümlerle pazarlama birimlerinin performansının arttırılabileceği bir sipariş sıralama doğrusal karar modeli önerilmiş olup teslim tarihi problemi üzerine çalışan araştırmacılara yeni bir perspektif önerilmiştir.

\section{Kaynakça}

Aspvall, B., Flåm, S. D., \& Villanger, K. P. (1995). Selecting among scheduled projects. Operations research letters, 17(1), 37-40.

Assarzadegan, P., \& Rasti-Barzoki, M. (2016). Minimizing sum of the due date assignment costs, maximum tardiness and distribution costs in a supply chain scheduling problem. Applied Soft Computing, 47, 343-356.

Baker, K. R., \& Trietsch, D. (2015). Trading off due-date tightness and job tardiness in a basic scheduling model. Journal of Scheduling, 18(3), 305-309.

Çakar, T., Köker, R., \& Canay, O. (2015). A new neuro-dominance rule for single-machine tardiness problem with double due date. Neural Computing and Applications, 26(6), 1439-1450.

Canıyılmaz, E., Benli, B., \& Ilkay, M. S. (2015). An artificial bee colony algorithm approach for unrelated parallel machine scheduling with processing set restrictions, job sequencedependent setup times, and due date. The International Journal of Advanced Manufacturing Technology, 77(9-12), 2105-2115.

Carr, S., \& Duenyas, I. (2000). Optimal admission control and sequencing in a make-tostock/make-to-order production system. Operations research, 48(5), 709-720.

Chaharsooghi, S. K., Honarvar, M., \& Modarres, M. (2011). A multi-stage stochastic programming model for dynamic pricing and lead time decisions in multi-class make-toorder firm. Scientia Iranica, 18(3), 711-721.

Charnsirisakskul, K., Griffin, P. M., \& Keskinocak, P. (2004). Order selection and scheduling with leadtime flexibility. IIE transactions, 36(7), 697-707.

Charnsirisakskul, K., Griffin, P. M., \& Keskinocak, P. (2006). Pricing and scheduling decisions with leadtime flexibility. European Journal of Operational Research, 171(1), 153-169. 
Chen, C. S., Mestry, S., Damodaran, P., \& Wang, C. (2009). The capacity planning problem in make-to-order enterprises. Mathematical and computer modelling, 50(9), 1461-1473.

Conway, R. W., Maxwell, W. L., \& Miller, L. W. (1967). Theory of scheduling. Courier Corporation.

Demir, H. İ., \& Erden, C. (2017). Solving process planning and weighted scheduling with WNOPPT weighted due-date assignment problem using some pure and hybrid metaheuristics. Sakarya Üniversitesi Fen Bilimleri Enstitüsü Dergisi, 21(2), 210-222.

Demir, H. I., Cil, I., Uygun, O., Simsir, F., \& Kokcam, A. H. (2016). PROCESS PLANNING AND WEIGHTED SCHEDULING WITH WNOPPT WEIGHTED DUE-DATE ASSIGNMENT USING HYBRID SEARCH FOR WEIGHTED CUSTOMERS. MATTER: International Journal of Science and Technology, 2(1).

Demir, H. I., Uygun, O., Cil, I., Ipek, M., \& Sari, M. (2015). Process Planning and Scheduling with SLK Due-Date Assignment where Earliness, Tardiness and Due-Dates are Punished. Journal of Industrial and Intelligent Information Vol, 3(3).

Deng, H., Wang, Q., Leong, G. K., \& Sun, S. X. (2008). The usage of opportunity cost to maximize performance in revenue management. Decision Sciences, 39(4), 737-758.

Drwal, M. (2017). Robust scheduling to minimize the weighted number of late jobs with interval due-date uncertainty. arXiv preprint arXiv:1708.03252.

Duenyas, I. (1995). Single facility due date setting with multiple customer classes. Management Science, 41(4), 608-619.

Duenyas, I., \& Hopp, W. J. (1995). Quoting customer lead times. Management Science, 41(1), 43-57.

Easton, F. F., \& Moodie, D. R. (1999). Pricing and lead time decisions for make-to-order firms with contingent orders. European Journal of operational research, 116(2), 305-318.

Ebadian, M., Rabbani, M., Jolai, F., Torabi, S. A., \& Tavakkoli-Moghaddam, R. (2008). A new decision-making structure for the order entry stage in make-to-order environments. International Journal of Production Economics, 111(2), 351-367.

Foreest, N. D., Wijngaard, J., \& Van Der Vaart, T. (2010). Scheduling and order acceptance for the customised stochastic lot scheduling problem. International Journal of Production Research, 48(12), 3561-3578.

Germs, R., \& van Foreest, N. D. (2013). Order acceptance and scheduling policies for a maketo-order environment with family-dependent lead and batch setup times. International Journal of Production Research, 51(3), 940-951.

Gharehgozli, A. H., Rabbani, M., Zaerpour, N., \& Razmi, J. (2008). A comprehensive decisionmaking structure for acceptance/rejection of incoming orders in make-to-order environments. The International Journal of Advanced Manufacturing Technology, 39(910), 1016-1032.

Gordon, V. S., \& Strusevich, V. A. (2009). Single machine scheduling and due date assignment with positionally dependent processing times. European Journal of Operational Research, 198(1), 57-62. 
Guhlich, H., Fleischmann, M., \& Stolletz, R. (2015). Revenue management approach to due date quoting and scheduling in an assemble-to-order production system. OR Spectrum, 37(4), 951-982.

Gupta, S. K., Kyparisis, J., \& Ip, C. M. (1992). Note-Project selection and sequencing to maximize net present value of the total return. Management Science, 38(5), 751-752.

Ilić, A. (2015). On the variable common due date, minimal tardy jobs bicriteria two-machine flow shop problem with ordered machines. Theoretical Computer Science, 582, 70-73.

Jagan, D., Senthilvel, A. N., Prabhakar, R., \& Maheswari, S. U. (2015). Analysis for Maximal Optimized Penalty for the Scheduling of Jobs with Specific Due Date on a Single Machine with Idle Time. Procedia Computer Science, 47, 247-254.

Kalantari, M., Rabbani, M., \& Ebadian, M. (2011). A decision support system for order acceptance/rejection in hybrid MTS/MTO production systems. Applied Mathematical Modelling, 35(3), 1363-1377.

Kaminsky, P., \& Hochbaum, D. (2004). Due date quotation models and algorithms. Handbook of Scheduling: Algorithms, Models, and Performance Analysis, 1-34.

Keskinocak, P., Ravi, R., \& Tayur, S. (2001). Scheduling and reliable lead-time quotation for orders with availability intervals and lead-time sensitive revenues. Management Science, 47(2), 264-279.

Khataie, A. H., Bulgak, A. A., \& Segovia, J. J. (2011). Activity-based costing and management applied in a hybrid decision support system for order management. Decision Support Systems, 52(1), 142-156.

Kuroda, M. (2016). Integration of product design and manufacturing through real-time duedate estimation and scheduling systems. Journal of Advanced Mechanical Design, Systems, and Manufacturing, 10(3), JAMDSM0042-JAMDSM0042.

Lee, I. S., \& Sung, C. S. (2008). Single machine scheduling with outsourcing allowed. International Journal of Production Economics, 111(2), 623-634.

Leitch, R. A., Philipoom, P. R., \& Fry, T. D. (2005). Opportunity costing decision heuristics for product acceptance decisions. Journal of Management Accounting Research, 17(1), 95-117.

Lewis, H. F., \& Slotnick, S. A. (2002). Multi-period job selection: planning workloads to maximize profit. Computers \& Operations Research, 29(8), 1081-1098.

Li, M., Yao, L., Yang, J., \& Wang, Z. (2015). Due date assignment and dynamic scheduling of one-of-a-kind assembly production with uncertain processing time. International Journal of Computer Integrated Manufacturing, 28(6), 616-627.

Li, S. S., \& Chen, R. X. (2017). Common due date assignment and cumulative deterioration scheduling on a single machine. Engineering Optimization, 49(6), 976-989.

Lin, Y. K., \& Huang, D. H. (2017). Reliability analysis for a hybrid flow shop with due date consideration. Reliability Engineering \& System Safety.

Lödding, H., \& Piontek, A. (2017). The surprising effectiveness of earliest operation due-date sequencing. Production Planning \& Control, 28(5), 459-471. 
Low, C., Li, R. K., \& Wu, G. H. (2016). Minimizing Total Earliness and Tardiness for Common Due Date Single-Machine Scheduling with an Unavailability Interval. Mathematical Problems in Engineering, 2016.

Low, C., Li, R. K., Wu, G. H., \& Huang, C. L. (2015). Minimizing the sum of absolute deviations under a common due date for a single-machine scheduling problem with availability constraints. Journal of Industrial and Production Engineering, 32(3), 204-217.

Lu, L., Liu, Z., \& Qi, X. (2013). Coordinated price quotation and production scheduling for uncertain order inquiries. IIE transactions, 45(12), 1293-1308.

Moodie, D. R. (1999). Demand management: The evaluation of price and due date negotiation strategies using simulation. Production and Operations Management, 8(2), 151.

Moodie, D. R. (1999). Due date demand management: negotiating the trade-off between price and delivery. International Journal of Production Research, 37(5), 997-1021.

Mor, B., Mosheiov, G., \& Shabtay, D. (2013). A note: Minmax due-date assignment problem with lead-time cost. Computers \& Operations Research, 40(8), 2161-2164.

Nandi, A., \& Rogers, P. (2004). Using simulation to make order acceptance/rejection decisions. Simulation, 80(3), 131-142.

Nobibon, F. T., \& Leus, R. (2011). Exact algorithms for a generalization of the order acceptance and scheduling problem in a single-machine environment. Computers \& Operations Research, 38(1), 367-378.

Nurainun, T., Fudholi, A., Hartati, M., Yendra, R., \& Kusumanto, I. (2016). A Multi Due Date Batch Scheduling Model on Dynamic Flow Shop to Minimize Total Production Cost.

Oğuz, C., Salman, F. S., \& Yalçın, Z. B. (2010). Order acceptance and scheduling decisions in make-to-order systems. International Journal of Production Economics, 125(1), 200-211.

Patil, R. J. (2010). Due date management to improve customer satisfaction and profitability. International Journal of Logistics: Research and Applications, 13(4), 273-289.

Philipoom, P. R., \& Fry, T. D. (1992). Capacity-based order review/release strategies to improve manufacturing performance. The International Journal Of Production Research, 30(11), 2559-2572.

Philipoom, P. R., \& Fry, T. D. (1999). Order review/release in the absence of adherence to formal scheduling policies. Journal of Operations Management, 17(3), 327-342.

Pibernik, R., \& Yadav, P. (2008). Dynamic capacity reservation and due date quoting in a maketo-order system. Naval Research Logistics (NRL), 55(7), 593-611.

Raaymakers, W. H., Bertrand, J. W. M., \& Fransoo, J. C. (2000). The performance of workload rules for order acceptance in batch chemical manufacturing. Journal of Intelligent Manufacturing, 11(2), 217-228.

Rom, W. O., \& Slotnick, S. A. (2009). Order acceptance using genetic algorithms. Computers \& Operations Research, 36(6), 1758-1767.

Samarghandi, H., \& Behroozi, M. (2016). An Enumeration Algorithm for the No-Wait Flow Shop Problem with Due Date Constraints. IFAC-PapersOnLine, 49(12), 1803-1808.

Schäfer, R., Chankov, S., \& Bendul, J. (2016). What is Really "On-Time”? A Comparison of Due Date Performance Indicators in Production. Procedia CIRP, 52, 124-129. 
Senju, S., \& Toyoda, Y. (1968). An approach to linear programming with 0-1 variables. Management Science, B196-B207.

Shabtay, D., Steiner, G., \& Zhang, R. (2016). Optimal coordination of resource allocation, due date assignment and scheduling decisions. Omega, 65, 41-54.

Slotnick, S. A., \& Morton, T. E. (2007). Order acceptance with weighted tardiness. Computers \& Operations Research, 34(10), 3029-3042.

Snoek, M. (2000, November). Neuro-genetic order acceptance in a job shop setting. In Proceedings of the 7th International Conference on Neural Information Processing (pp. 815-819).

Vig, M, M. and Dooley, K. J., 1991, Dynamic rules for due-date assignment. International Journal of Production Research, 29, 1361 1377.

WU, M. C., \& Chen, S. Y. (1996). A cost model for justifying the acceptance of rush orders. International Journal of Production Research, 34(7), 1963-1974.

Yang, B., \& Geunes, J. (2007). A single resource scheduling problem with job-selection flexibility, tardiness costs and controllable processing times. Computers \& Industrial Engineering, 53(3), 420-432.

Yoon, S. W., \& Nof, S. Y. (2011). Cooperative production switchover coordination for the realtime order acceptance decision. International Journal of Production Research, 49(6), $1813-1826$.

Zahedi, Z., Samadhi, T., Suprayogi, S., \& Halim, A. (2016). Integrated batch production and maintenance scheduling for multiple items processed on a deteriorating machine to minimize total production and maintenance costs with due date constraint. International Journal of Industrial Engineering Computations, 7(2), 229-244.

Zhao, C. (2016). Common due date assignment and single-machine scheduling with release times to minimize the weighted number of tardy jobs. Japan Journal of Industrial and Applied Mathematics, 33(1), 239-249.

Zorzini, M., Corti, D., \& Pozzetti, A. (2008). Due date (DD) quotation and capacity planning in make-to-order companies: Results from an empirical analysis. International Journal of Production Economics, 112(2), 919-933. 


\section{EXTENDED ABSTRACT}

\section{DELIVERY DATE PROBLEM AND AN INNOVATIVE DECISION MODEL PROPOSAL}

Determining the delivery date of the products for the companies producing make-to-order production has a vital importance in terms of the profitability of the business and customer satisfaction. Because the customer must also be satisfied by the delivery date of the product as much as its price, the quantity submitted by the customer can be converted into finalized orders. Early delivery deadlines can cause trouble in relations with the firm's capacity, and late delivery dates lead to lose orders and customers. Looking at the previous studies, researchers seem to approach problem only from a certain angle, such as; the customer satisfaction, capacity planning, income or profit maximization. But proposed decision model is balancing all of them with the use of different weighting coefficients. These criteria are customer and order criteria that form the objective function. The proposed model shows that ranking the orders is more beneficial for the firm than considering a number of criteria rather than a single criterion. Thus, marketing processes can be improved by this model and the profitability of the company can be increased because of choosing the maximum revenue-generating order from decision models. In this respect, innovative transformations will be achieved in marketing units. In this study, we handled the delivery date assignment problem within the make-to-order production environment. Unlike previous studies, we propose an ideal and innovative linear decision model that orders can be sorted by this model with a multi-criteria decision to reach the objectives of the firm and companies also would have found a solution to the problem of determining the order delivery date. 